\title{
Construction on College English Mobile Learning Resources
}

\author{
Shaojie Wang \\ Foreign Language Department, Liaoning Institute of Science and Technology, Benxi, 117004, \\ China \\ phoenixjessie@126.com
}

Keywords: college English; mobile learning; resources construction; learning mode; construction process; resources organization

\begin{abstract}
To carry out mobile learning in college English teaching, establish the students as the center, self-control learning process, personalized learning to explore a new way. In this paper, the current situation and difficulties of college English mobile learning resource construction are studied. First of all, the study of college English mobile learning model, including the local model, network model and search engine model; and then, combined with software development process to study the construction of mobile learning resources; then, the construction of mobile learning resource is studied by combining the process of software development. Finally, the organization of college English mobile learning resources is described in the form of micro courseware, network course, micro blog, and micro video and electronic materials. The research results of this paper provide methods and ideas for the construction of college English mobile resources.
\end{abstract}

\section{Introduction}

"College English curriculum teaching requirements" pointed out that all colleges and universities should make full use of modern information technology, based on computer and classroom teaching mode to improve the teaching of teachers in a single teaching mode. The new teaching mode should be based on modern information technology, especially network technology, so that English teaching and learning cannot be limited by time and place in a certain extent, towards the direction of individualized and autonomous learning. The new teaching mode should embody the combination of English teaching practice, knowledge and interest, which is conducive to mobilize the enthusiasm of teachers and students in two aspects, in particular, to reflect the main role of students in the teaching process and the leading role of teachers in the teaching process. While making full use of modern information technology, it is reasonable to inherit the excellent part of the traditional teaching mode, and to take advantage of the traditional teaching.

With the rapid development of network technology and communication technology, CDMA, WAP and GPRS technologies have been developed and applied in various fields, Internet is no longer limited to desktop computers, mobile digital devices (such as portable computers, smart phones, PDA, iPad, etc.) are not limited to desktop computers. Mobile learning is a new learning model, which has the characteristics of mobility, interaction, sharing and personalized learning, which can reflect the combination of English teaching practice, knowledge and interest. It can satisfy the learners' desire to obtain any content at any time and at any place, Meet the requirements of the students on mobile learning, personalized learning and lifelong learning, and gradually become a popular way of learning, by people's attention. Mobile learning is conducive to mobilize the enthusiasm of teachers and students in two aspects, in particular, to reflect the students in the teaching process of the main position and teachers in the teaching process of the leading role.

Mobile learning resources are the important components of the mobile learning system. It is an important component of the mobile learning system. There is a big difference between the mobile learning resources and the common learning resources, which is the characteristic of mobile learning [1]. Mobile learning resources must comply with the conditions of mobile learning, that is, to support mobile learning device remote access, browse, search, download and other functions, the information carrying capacity cannot be too large, to meet the needs of mobile learning content fragmentation, can smooth the teaching activities and two-way, multi direction interaction. This 
paper is aimed at the current situation and problems of the construction of College English mobile learning resources, which is based on the construction of College English mobile learning resources.

\section{Mode on College English Mobile Learning}

Learning mode is the way to make a person achieve the best learning state. College English mobile learning model includes three types, namely, the local mobile learning model, the mobile learning model of the network and the mobile learning model of the search engine, as shown in Fig. 1.

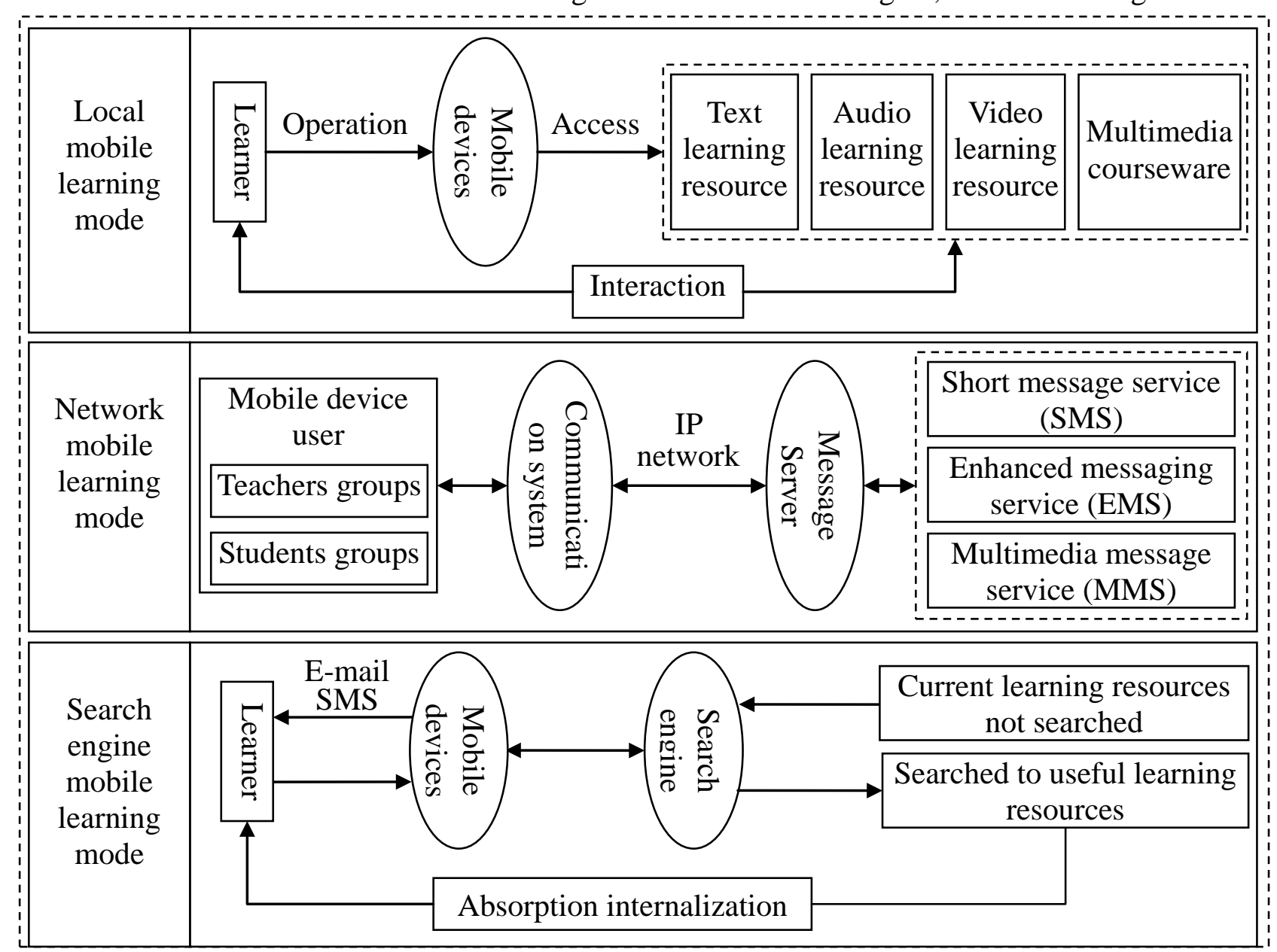

Fig. 1. Mobile learning mode

(1) Local mobile learning model. The learner chooses the appropriate e-learning resources and studies the mobile devices. This learning mode is not required for the network connection, learners only have MP3 or MP4 player, smart phone, PDA or notebook computer, etc., to install the corresponding learning software, the mobile learning resources to download the corresponding devices, and you can carry out the study. Learners can control the learning progress, repeat the key and difficult content, and record the learning notes in the form of recording function or writing, in order to achieve the purpose of strengthening and consolidating the knowledge.

(2) Network mobile learning model. Mainly through the mobile phone short message to learn. Because of the acceptance of information is not limited by time and place, beautiful images make up for the lack of traditional media, which provides a new way for students to cooperate with each other. Students and teachers use smart phones to send short messages to mobile communication systems, mobile communication system through the IP network to transmit data to the short message server and data content analysis and processing, the short message server will be processed after the results returned to the information sender's mobile phone, thus completing the short message learning activities.

(3) Search engine for mobile learning mode. According to the situation of the students, the 
search engine is fast, accurate and convenient to obtain the learning resources and meet the demand of informal learning. The key part of this model is that the students will generalize the problem situation to search keywords, search for effective learning resources, deepen the understanding of the knowledge, and achieve the expansion of knowledge through the expansion of the resources. For the time being no optimal search results of the resources, the learner can be customized search task by email or SMS, waiting for the search engine will search results sent to his mailbox or mobile phone short message.

\section{Construction Process on Mobile Learning Resources}

The software development process, including system research, feasibility studies, needs analysis, outline design, detailed design, encoding implementation and system testing, etc.. Combined with the software development process design of mobile learning resource construction process as shown in Fig. 2, the left arrow is from top to bottom, indicating the construction process; the right arrow is from the bottom up, indicating the modification and improvement process [2].

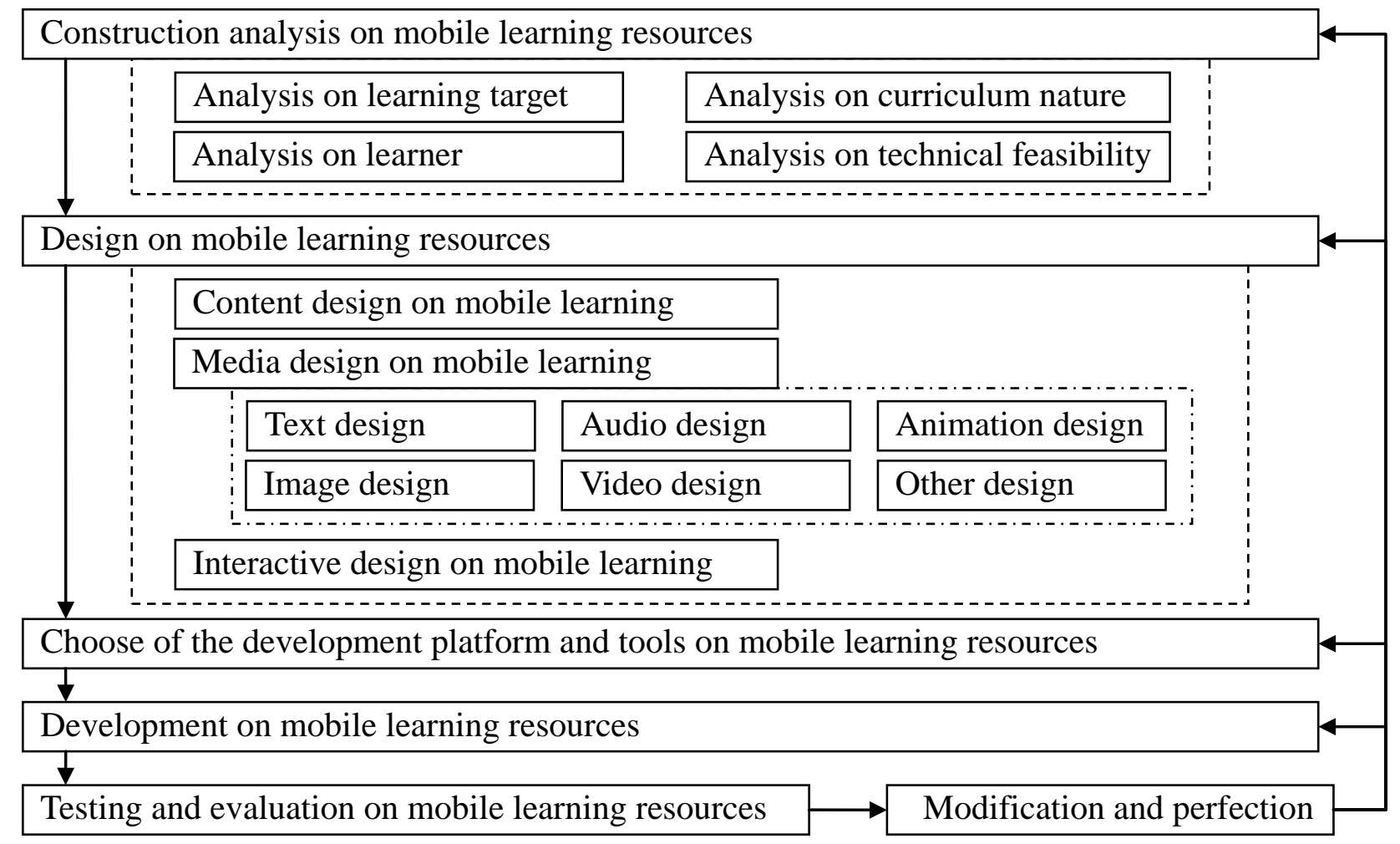

Fig. 2. Construction process on mobile learning resources

(1) Building analysis of mobile learning resources. Before the construction of resources, we should analyze the relevant content based on the system research. First of all, we should carry out technical analysis, consider all the technical issues involved in the construction of the resources, use the mature technology as far as possible, carefully introduce advanced technology, and then carry out other aspects of the analysis, including the learning objectives, learning analysis and the nature of the curriculum analysis.

(2) Mobile learning resource design. Content design should pay attention to the short and concise knowledge unit, which can stimulate and maintain the learning motivation and interest of the learners. The media design includes the design of text, pictures, audio, video and animation design. Interactive design consists of a relatively simple form of SMS, as well as a rich learning content.

(3) Mobile learning resource development tool selection. Currently, the development of mobile learning resources includes the following three platforms and tools, according to the actual situation to make a choice. IPhone platform, in the OS Mac system to build the development environment, the main tools are SDK iPhone and Xcode; Android platform, the general use of Eclipse+ADT 
plug-in, the installation is relatively simple; Mobile Windows platform, the best development tool is Studio Visual.

(4) Development of mobile learning resources [3, 4]. For mobile learning, it has the characteristics of learning convenience, personalization, fragment, interactive, situational relevance, etc., to create meaningful learning situations for learners, and to provide a learning strategy for learners' real situation, and to provide rich learning resources for learners to help them solve practical problems.

(5) Test and evaluation of mobile learning resources. Testing is the process of identifying the right, integrity, safety and quality of the resources. The mobile learning resources will be tested and evaluated, and the results can be used to modify the situation of the early stage of mobile learning analysis and resource design and timely adjustment of resource construction plan.

\section{Resources Organization on College English Mobile Learning}

For mobile learning resources, because of different media formats supported by different mobile devices. Therefore, in the development of resources should be based on the type of support for mobile devices to develop the material format. Through the analysis of several major mobile devices such as smart phones, PAD, portable computers, the text, images, audio, video and animation are summarized. The organization of these five materials can include text messages, web pages, micro courseware, e-books, electronic materials, animation, audio and video, e-mail, microblogging, custom and other ways, limited to the length of the article, this article is only the most commonly used in several ways to explain [5-10].

(1) Micro courseware. Micro courseware is actually a micro courseware, which is specially used in various new media platforms. It is suitable for the use of learning software in the mobile state and the short-term leisure state. And ordinary courseware, micro courseware can provide a wealth of multimedia performance and hypertext structure, but also with the presentation of teaching content, control teaching process, evaluation of learning results, improve learning interest and other functions. But the teaching content of the micro courseware is generally small, and the learning time is short. Listening, speaking, reading, translation, vocabulary, etc. can be made into a micro courseware form. Highlight the difficulties of teaching, effective teaching content, to stimulate students' learning interest, and promote students' initiative to explore thinking and creative study.

(2) Network course. The State advocates the construction of quality courses, and requires the Internet, so as to realize the high quality resource sharing, the network curriculum is the most important way to achieve this requirement. Network course is the teaching content and the implementation of the teaching activities through the network performance of the combined, is the information era of the new conditions of the performance. In the advanced educational ideas, teaching theory and learning theory, based on Web, the learning process has the characteristics of interaction, sharing, openness, cooperation and autonomy. To concentrate on the excellent teacher resources, make the university English into the network curriculum, on the one hand to facilitate the students to study independently; on the other hand to solve many college English teachers lack the present situation.

(3) Micro blog. Micro Blog Application in mobile learning, can promote the development of mobile learning, while playing the advantages of micro blog, which is determined by the characteristics of the micro blog and mobile learning characteristics. To provide a wide range of potential learners, any one of the Web2.0 technology are not the development of the speed and mass basis for the micro blog. Full play to the study of the mobility and convenience, through the SMS to carry out information browsing and publishing, can promote the learning of mobility and convenience. Is conducive to the creation of positive and harmonious interpersonal relationships, promote mobile learning in the interpersonal relationship, to help learners build a network of contacts. Easy to combine with other technologies, it can be easily combined with video, audio, pictures and other multimedia technology.

(4) Micro video. Micro video refers to 30 seconds to 20 minutes of video clips. The content of the micro video covers a wide range of video forms, covering a micro film, a short film, DV video 
clips, video clips, advertising, etc.. With the continuous development of production technology and playing technology, the good effect of micro video in the study of English language learning is presented. Compared with other learning methods, has the unique advantages, such as excellent content, simple refining, abundant resources, flexible time, entertainment, and so on. In the context of mobile learning, micro video design should take full consideration of its own characteristics, considering the characteristics of the mobile terminal and the external network, to design a more scientific, reasonable, personalized features of mobile learning video resources.

(5) Electronic teaching material. As a new type of digital learning resources, electronic teaching material is good for the students to read the law, and it is good for the organization to study and meet the requirements of the curriculum objectives. Electronic materials and paper materials is not a simple copy, but has interactive function, a variety of media integration, the content is very rich set of features, learning content and services in one. It is not only satisfied with the students' independent learning, but also serves for the traditional classroom teaching. It is not only the main learning resources to support the teaching activities, but also the important cognitive tools to support the teaching activities. Because the electronic textbook is rich, interactive, dynamic and energy-saving environmental protection and other characteristics, has gradually become the ideal mobile learning resources, meet the needs of learners' classroom or autonomous learning.

\section{Conclusion}

As the third development stages of distance education, mobile learning is a new learning model which is based on wireless network and mobile communication equipment to acquire learning resources and learning support services. It is a hot point of research in the field of educational technology [11]. English is a highly practical discipline, including a lot of listening, speaking, reading, writing and so on. Using mobile learning in English teaching is not only beneficial to the development of theoretical knowledge, but also conducive to carry out the interaction between students and teachers and students, to meet the needs of students' flexibility learning, to stimulate students' participation in language learning, to effectively compensate for the shortcomings of traditional classroom teaching, improve students' autonomous learning ability. In College English teaching, to carry out mobile learning, in order to establish the students as the center, self-control learning process, personalized learning to explore a new way. Students can get pictures whenever and wherever possible static and dynamic combination of resources, is conducive to stimulate learners' interest in learning English, autonomous learning ability, is conducive to enhancing students' English listening and speaking ability, improve the students' English comprehensive application ability for college students in an increasingly competitive society to increase competitiveness, but also conducive to the improvement of College English teaching. The research results of this paper provide methods and ideas for the construction of College English mobile resources, and have important significance to mobilize the enthusiasm of students and improve the level of College English teaching.

\section{References}

[1] Y. Wei, M. D. Liu, "New Transition: On college English Teaching in M-learning," Journal of Hunan First Normal University, vol. 15, no. 2, pp. 48-51, 2015.

[2] H. G. Fang, Y. Mao, J. Liu, H. Y. Wang "Research of System Support Environment of Mobile Learning," Modern Educational Technology, vol. 21, no. 3, pp. 15-20, 2011.

[3] Z. J. Yu, "Technology analysis of mobile learning resource development," Journal of ABC Wuhan Management Institute, vol. 23, no. 6, pp. 61-63, 2013. 
[4] H. M. Jia, "A study on the construction of College English mobile learning resources based on the theory of Situated Cognition," Journal of Chifeng University (Philosophy and Social Science Chinese Edition), vol. 36, no. 10, pp. 270-271, 2015.

[5] Y. Li, J. L. Weng. "Research on the design of micro learning video resources in the perspective of mobile learning," Software Guide, vol. 12, no. 2, pp. 179-181, 2013.

[6] W. Q. Zhao, The Design and Development of Interactive E-Textbook for Mobile Learning," Master's degree of Sichuan Normal University, 2014.

[7] J. Q. Wu, L. L. Qi, P. W. Hu, Y. B. Yuan "Learning activity design of micro courseware," China Audio Visual Education, vol. 33, no. 9, pp. 106-109, 2012.

[8] Baidu Encyclopedias, "Network course," https:/www.baidu.com/s?ie8\&rsv_bpb2f7ba6b00031768\&rsv_t=6e97QXluum\%2FlnSENyh6o 7u3KklAS0ivRjZkPuInpHHlywR3\%2F3XtQzHZFzpp5\%2FlVi4zUx\&rsv_enter, 2015-12-2.

[9] W. Q. Zhao, Application of multimedia courseware and network course in Teaching," Teaching in Chinese Universities, vol. 29, no. 5, pp. 74-77, 2007.

[10] R. Li, "The construction of College English teaching materials supporting mobile learning resources system," Technology and publishing, vol. 33, no. 8, pp. 107-110, 2014.

[11] C. E. Chen, "Research on teaching design of mobile learning resources," Master's degree of Southwest Jiao Tong University, 2012. 